\title{
A systematic review and meta-analysis of 24-h urinary output of children and adolescents: impact on the assessment of iodine status using urinary biomarkers
}

\author{
Kelsey Beckford ${ }^{1}$ (D ) Carley A. Grimes ${ }^{1}$. Claire Margerison ${ }^{1} \cdot$ Lynn J. Riddell $^{1} \cdot$ Sheila A. Skeaff $^{2} \cdot$ Madeline L. West $^{1}$. \\ Caryl A. Nowson ${ }^{1}$
}

Received: 19 June 2019 / Accepted: 18 November 2019 / Published online: 29 November 2019

(c) The Author(s) 2019

\begin{abstract}
Purpose Urinary iodine concentration (UIC $(\mu \mathrm{g} / \mathrm{ml})$ from spot urine samples collected from school-aged children is used to determine the iodine status of populations. Some studies further extrapolate UIC to represent daily iodine intake, based on the assumption that children pass approximately $1 \mathrm{~L}$ urine over $24-\mathrm{h}$, but this has never been assessed in population studies. Therefore, the present review aimed to collate and produce an estimate of the average 24-h urine volume of children and adolescents ( $>1$ year and $<19$ years) from published studies.

Methods EBSCOHOST and EMBASE databases were searched to identify studies which reported the mean 24-h urinary volume of healthy children ( $>1$ year and $<19$ years). The overall mean $(95 \% \mathrm{CI})$ estimate of 24 -h urine volume was determined using a random effects model, broken down by age group.

Results Of the 44 studies identified, a meta-analysis of 27 studies, with at least one criterion for assessing the completeness of urine collections, indicated that the mean urine volume of 2-19 year olds was $773(654,893)(95 \% \mathrm{CI}) \mathrm{mL} / 24-\mathrm{h}$. When broken down by age group, mean $(95 \%$ CI) 24 -h urine volume was $531 \mathrm{~mL} /$ day $(454,607)$ for $2-5$ year olds, $771 \mathrm{~mL} / \mathrm{day}$ $(734,808)$ for $6-12$ year olds, and $1067 \mathrm{~mL} /$ day $(855,1279)$ for $13-19$ year olds.

Conclusions These results demonstrate that the average urine volume of children aged 2-12 years is less than $1 \mathrm{~L}$, therefore, misclassification of iodine intakes may occur when urine volumes fall below or above $1 \mathrm{~L}$. Future studies utilizing spot urine samples to assess iodine status should consider this when extrapolating UIC to represent iodine intakes of a population.
\end{abstract}

Keywords Iodine $\cdot$ Urine $\cdot$ Urine volume $\cdot$ Children $\cdot$ Adolescents $\cdot$ Nutrition $\cdot$ Assessment

\begin{abstract}
Abbreviations
DONALD Dortmund Nutritional and Anthropometric Longitudinally Designed Study

NOS Newcastle-Ottawa scale

PRISMA Preferred Reporting Items for Systematic

Review and Meta-Analysis
\end{abstract}

Electronic supplementary material The online version of this article (https://doi.org/10.1007/s00394-019-02151-w) contains supplementary material, which is available to authorized users.

Kelsey Beckford

k.beckford@deakin.edu.au

1 Institute for Physical Activity and Nutrition, Deakin University, Locked Bag 20000, Waurn Ponds, Geelong, VIC 3220, Australia

2 Department of Human Nutrition, University of Otago, 362 Leith St, North Dunedin, Dunedin 9016, New Zealand
UIC
UIE
WHO
Urinary iodine concentration
Urinary iodine excretion
World Health Organization

\section{Introduction}

Monitoring the iodine nutrition of populations and individuals is important to identify those at risk of deficiency, as deficiencies during childhood have been linked with impaired cognitive and motor functions in schoolchildren [1, 2]. Current recommendations for assessing the iodine nutrition of populations using spot urine samples from school-aged children were developed by the World Health Organization (WHO) over a number of years (1986-2007) [3-7]. Whilst the original version of these recommendations was based on the association between a daily estimated iodine intake, extrapolated from creatinine 
excretion, equivalent to $100 \mu \mathrm{g}$ of iodine and reduced goiter prevalence among children and adults [8], later iterations extrapolated this value to represent a concentration, urinary iodine concentration (UIC), expressed as $\mu \mathrm{g} / \mathrm{L}$ [6]. Whilst these recommendations were originally developed as a marker of iodine status within populations, some studies have utilized UIC from spot urine samples as an indicator of iodine intake [9-14]. In such instances, issues may arise as UIC would only be reflective of daily intake if urine volume was equivalent to $1 \mathrm{~L}$. For example, in a population with a daily urinary volume of $1 \mathrm{~L}$, a UIC of $100 \mu \mathrm{g} / \mathrm{L}$ could be extrapolated to be indicative of a daily iodine intake of $100 \mu \mathrm{g} / 24-\mathrm{h}$. As this value is equal to the daily intake originally associated with reduced goiter prevalence [8], this population can be classified as having a sufficient iodine intake. However, in a population of children with a daily urine volume closer to $0.5 \mathrm{~L}$, a UIC of $100 \mu \mathrm{g} / \mathrm{L}$ may be indicative of a daily iodine intake closer to $50 \mu \mathrm{g} / 24-\mathrm{h}$. This could result in the misclassification of this population as iodine sufficient when their daily iodine intake may, in fact, place them at risk of developing iodine deficiency disorders.

Therefore, iodine monitoring programs which have extrapolated daily iodine intake from UIC determined from spot urine samples in populations of children and adolescents [9-14] and have not taken the lower daily urinary output into account, may be inaccurately estimating iodine intakes. As such, this may have resulted in the misclassification of populations as having sufficient iodine intakes, when their true intakes may be lower than the $100 \mu \mathrm{g} /$ day originally associated with reduced goiter prevalence. Such misclassifications may have prevented the implementation of necessary iodine fortification programs. To date, there has been no global systematic collation of the average 24-h urine volume of children and adolescents. This information could help researchers estimate population dietary iodine intake of children and adolescents from spot urine samples. Therefore, the aim of the current study was to estimate the average 24-h urine volume measured in healthy children and adolescents, by conducting a systematic review and meta-analysis of studies which have reported the 24-h urine volume of children and adolescents aged 2-19 years.

\section{Methods}

This protocol adheres to the Preferred Reporting Items for Systematic Review and Meta-Analysis Protocols (PRISMAP) 2015 statement [15] and was registered with the International Prospective Register of Systematic Reviews (PROSPERO) (registration number CRD42016033682).

\section{Information sources and search}

A search strategy was developed to identify papers published up to October 2018, which have reported the 24-h urine volume of children and adolescents ( $>1$ year and $\leq 19$ years). An electronic literature search of EBSCOHOST (MEDLINE complete, CINAHL, Academic Search Complete and Global Health) and EMBASE databases was conducted. The search strategy was developed in consultation with a research librarian. Free text keywords were used to conduct the search. Search criteria specific to each database are outlined in Table 1. The search strategy was piloted across each database to improve the effectiveness of the final search. Only peer-reviewed original research articles published in English and conducted in humans were included. It was beyond the scope of this review to include and examine sources from 'grey' literature. The reference lists of included studies identified through the search were also reviewed.

\section{Inclusion/exclusion criteria}

Only peer-reviewed original research studies were included and any reviews, meta-analyses, editorials, case reports, conference proceedings or other grey literature identified through the search were excluded at the screening stage. As the primary focus of this review was to determine the average daily urinary output of children and adolescents, only studies which reported the 24-h urinary output of healthy children and adolescents $>1$ and $\leq 19$ years of age were included. Where multiple published reports were available from the same study, the most recently published and/or the study with the largest sample size was included.

All papers identified from the initial electronic search process were imported into an Endnote library, and duplicates removed. Titles and abstracts were screened and studies included based on the eligibility criteria as outlined above. Two investigators (KB and MW) independently screened the titles and abstracts of the articles independently to assess eligibility for inclusion. If agreement was reached, articles were either excluded or moved to the next stage (full-text). If agreement was not reached, the article was moved to the full-text stage. Following this screening process, the full text of eligible studies was retrieved and studies which collected 24-h urine samples but did not report the final 24-h urine volume were excluded. At this stage, the reference lists of included studies were scanned, and the full text of any relevant studies retrieved and reviewed for inclusion. The PRISMA flow chart [16] was used to document the number of studies identified during the search process and those excluded and included according to the outlined eligibility criteria (Fig. 1). 
Table 1 Search criteria specifications for each database

\begin{tabular}{|c|c|c|}
\hline Database & Search options & Search terms \\
\hline \multicolumn{3}{|l|}{ EBSCOHOST } \\
\hline Academic search complete & $\begin{array}{l}\text { Limiters_full text; scholarly (peer reviewed) } \\
\text { journals; language: English } \\
\text { Search modes—boolean/phrase }\end{array}$ & $\begin{array}{l}\text { (“24 h urin*” OR "twenty four hour urin*” OR " } 24 \text { h urin*”) } \\
\text { AND } \\
\text { (sampl* OR collection* OR volume* OR excretion* OR output*) }\end{array}$ \\
\hline CINAHL complete & $\begin{array}{l}\text { Limiters-English language; peer reviewed } \\
\text { Search modes_boolean/phrase }\end{array}$ & $\begin{array}{l}\text { AND } \\
\text { (schoolchild* OR child* OR adolescen* OR teen*) }\end{array}$ \\
\hline Global health & $\begin{array}{l}\text { Limiters-language: English } \\
\text { Search modes_boolean/phrase }\end{array}$ & \\
\hline MEDLINE complete & $\begin{array}{l}\text { Limiters_English language; human } \\
\text { Search modes_boolean/phrase }\end{array}$ & \\
\hline EMBASE & $\begin{array}{l}\text { Advanced search } \\
\text { No mapping options used } \\
\text { No date limits specified } \\
\text { Sources: Embase only (Medline not } \\
\text { selected as separate search) } \\
\text { Field labels: abstract, article title, index } \\
\text { term and subheading } \\
\text { Quick limits: human, only in English } \\
\text { Publication types: article, article in press } \\
\text { EBM, gender, age and animal advanced } \\
\text { options left blank }\end{array}$ & $\begin{array}{l}\# 1: \text { ' } 24 \mathrm{~h} \text { urin*' OR 'twenty four hour urin*' OR ' } 24 \mathrm{~h} \text { urin*' OR } \\
\text { 'twenty four h urin*' } \\
\text { \#2: sampl* OR collection* OR volume* OR excretion*or AND } \\
\text { output* } \\
\text { \#3: child* OR adolescen* OR teen* } \\
\text { \#4: \#1 AND \#2 AND \#3 }\end{array}$ \\
\hline
\end{tabular}

As multiple studies had utilised data from the Dortmund Nutritional and Anthropometric Longitudinally Designed (DONALD) Study [17], cross-checking of study dates and participant characteristics was carried out to minimise participant overlap between the studies. Some studies $(n=7)$ [18-24] were excluded from the final analysis as they did not report which years of data collection had been analysed, therefore, possible participant overlap with other studies could not be determined. No additional information apart from that published was available from authors. Where participant overlap was possible, the study with the larger participant number was included in the final analysis. Of the 27 DONALD studies initially identified, six studies [25-30] were considered for the final analyses as they captured the full range of data collection years and included the largest number of participants whilst minimising possible participant overlap.

\section{Data extraction and synthesis}

Data extraction was completed using a data extraction template (Table 2). The template was initially piloted on five eligible studies and modifications made where necessary. As 24-h urinary creatinine excretion either alone, in relation to expected creatinine based on sex and/or weight, is often used as a marker for complete urine collection under the assumption that urinary creatinine excretion, as an indicator of body mass is stable within individuals from day to day [31-33], data pertaining to $24-\mathrm{h}$ excretion of creatinine was also extracted where reported.

\section{Quality assessment}

The quality of the studies included in this review was assessed using a modified version of the Newcastle-Ottawa scale (NOS) for cohort studies [34], as all studies included in the final synthesis were of a cross-sectional study design. The NOS was modified to suit the context of the studies included in the review and particular consideration was made towards the 24-h urine collection methods used in each study. This scale assigns stars to indicate higher quality based on three broad criteria specific to the design of the study: (1) selection (representativeness of the study sample); (2) comparability of the findings (normalisation of the results to a 24-h period); and (3) assessment of outcome (quality of the reported 24-h urine collection methodology) (Online Supporting Material). Studies were categorised as 'high' 'medium' or 'low' quality according to the number of stars they received (out of a maximum of 10 stars: low: 0-3; medium: 4-7; high 8-10). As only three studies provided sufficient detail on their urine collection protocol to be classified as "high" quality [35-37], we included a second category of quality assessment, based on studies which had reported at least one criterion for the assessment of urine collection completeness.

\section{Statistical analysis}

Following data extraction, data was collated and imported into STATA/SE 15.0 (StataCorp LP, College Station, TX, USA) for analysis. The main outcome variable was $24-\mathrm{h}$ 
Fig. 1 PRISMA flowchart

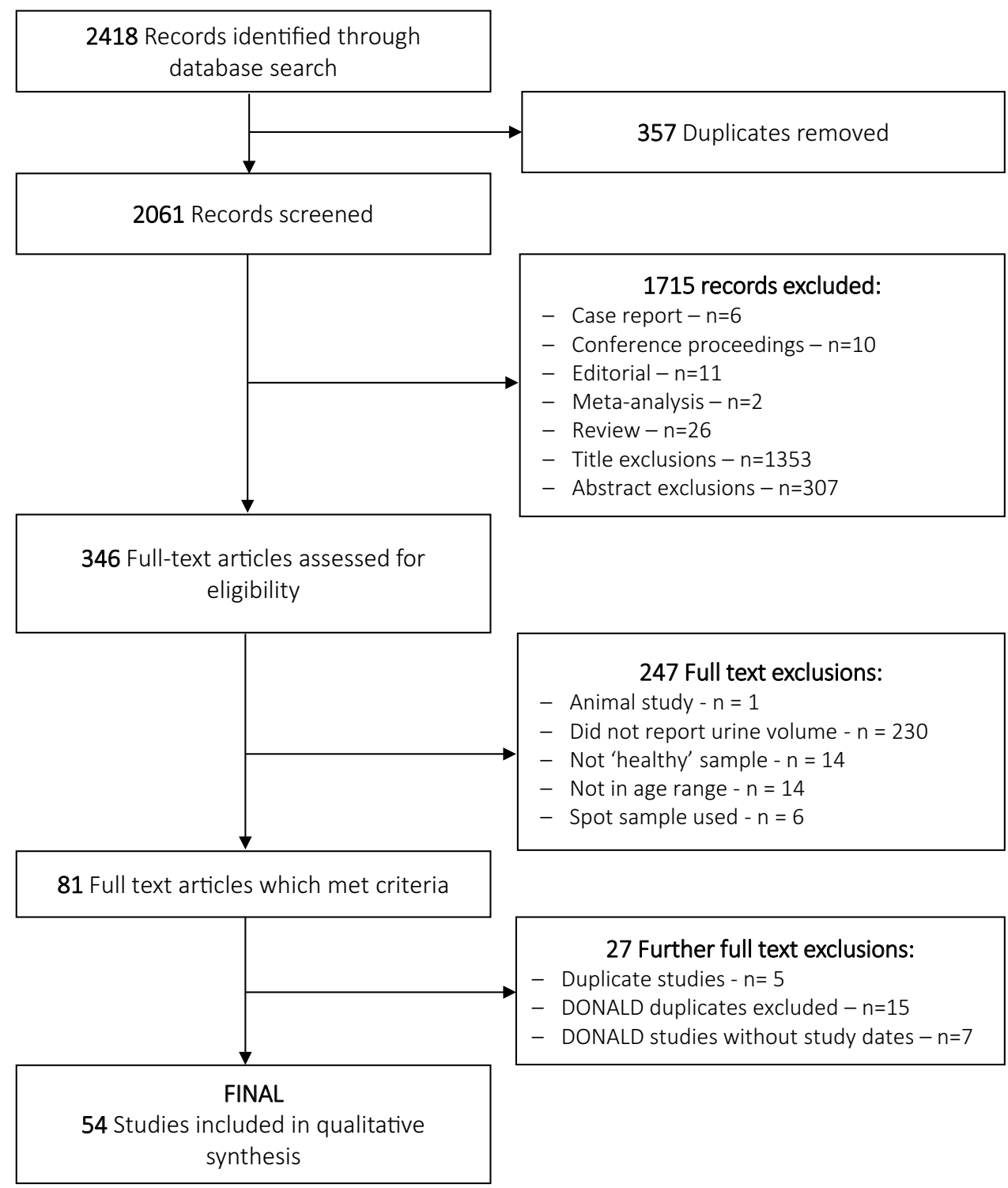

urine volume, presented in $\mathrm{mL} / 24-\mathrm{h}$. Of the 54 studies originally included, five did not include a measure of spread/ dispersion [38-42] and were subsequently excluded (Fig. 2). Most studies $(n=37)$ reported urine volume as mean (SD) or mean (SEM) [35-37, 43-76] (Table 3). Twelve studies reported urine volume as median, this included median (min, $\max ) n=4$ [77-80], median (IQR) $n=7$ [25, 26, 28-30, 81, 82], median (P3, P97) $n=1$ [83]. For the seven studies which reported median (IQR) (Table 4), the mean (SD) was extrapolated from the median (IQR) using the median as a proxy for the mean and the IQR as a proxy for the SD (i.e., P75-P25 = SD) [84]. The calculated mean (SD) for these studies was then pooled with the results of those studies which reported urine volume as mean (SD). As such, a total of 44 studies were considered for the primary analysis.

Due to the wide age range of participants of the included studies, studies were grouped into three groups according to the age of the participants; $2-5$ years (17 studies) [26, 28, 36, 43-45, 50, 51, 54-57, 60, 62, 68, 72, 74, 75], 6-12 years (20 studies) [25, 30, 35, 36, 45-48, $52,54,58,59,61,63-66,71,76,81]$ and 13 to $<19$ years (12 studies) [25, 26, 29, 36, 49, 53, 54, 63, 65, 67, 69, 81]. These cut-points were chosen based on the WHO criteria for assessing population iodine deficiency, which defines school-aged children as between 6 and 12 years of age [6]. As some studies presented results broken down by age group, a single study may have been assigned to multiple age groups. Studies which crossed the age group cut-offs were assigned to the age group in which the majority of the participants would fall (e.g., a study with participants 9-13 years [59] would fall into the 6-12 year age group. Four studies [37, 70, 73, 82] which encompassed very large age ranges (i.e., $>8$ years) were excluded from the sub group analyses using age cut offs. 
Table 2 Data extracted from included studies

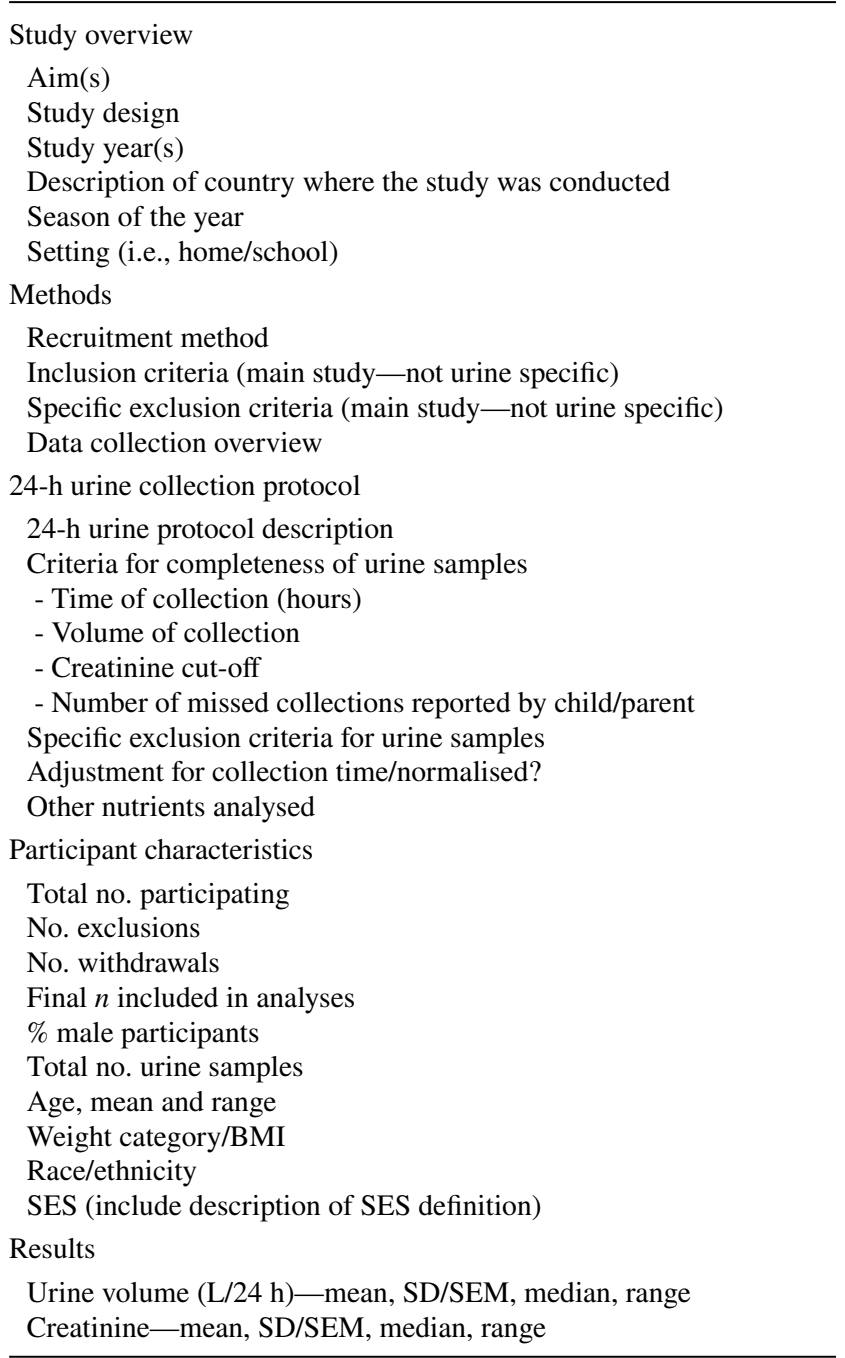

\section{Initial analysis}

The overall mean [95\% confidence interval (CI)] estimate of urine volume for all 44 studies was determined using a random effects model and presented for the group as a whole (i.e., 2-19 year olds), as well as broken down by age group.

\section{Primary analysis: studies with $\geq 1$ criterion for assessing the completeness of urine samples}

As the inclusion of criteria for assessing the completeness of urine collections can result in the exclusion of over/under collectors, the primary analysis was limited to only those studies which reported at least one criterion for assessing the completeness of the included urine samples $(n=27$, "Primary Analysis, Fig. 2). The overall mean (95\% CI) estimate of daily urine volume was determined using a random effects model and displayed in forest plots, broken down by age group.
A one-way ANOVA was used to assess the differences in urine volume across the three age groups. In addition, a one-way ANOVA was used to assess differences in the urine volume between those studies which did not report any criteria for assessing the completeness of included urine samples and those which reported $>1$ and $>2$ criteria. Tukey's post hoc tests were performed to determine significant differences between age subgroups. Heterogeneity was analysed using the $I^{2}$ and $Q$ statistics. The coefficient of variation $(\mathrm{CV})$ of the mean volume for each age group was derived from the mean and SD random effects analysis and was calculated by dividing the SD for each age group's urine volume by the mean and multiplying by 100. A two-sample $t$ test used to assess the difference in volumes determined for the initial analysis compared to the primary analysis (i.e., limited to studies with $>1$ criterion for assessing the completeness of the urine samples) across the three age groups. As 11 studies had presented the results broken down by gender [ 26 , $28-30,37,53,65,66,68,70,81]$, a two-sample $t$ test was used to evaluate the difference in 24-h urine volume between genders.

To examine whether climate had an impact on overall urine volume, studies were classified according to climate based on their proximity to the equator. Studies which were conducted in countries which lie between the Tropic of Cancer and Tropic of Capricorn (23.5 north and south) (2 studies) $[54,55]$ were classified as having a "warm" climate, whereas studies which fell outside of this area were classified as having a "cold" climate (25 studies) [25, 26, 28-30, 35-37, 43, 46, 48, 52, 56, 57, 60, 61, 64, 66, 67, 70, 73-75, $81,82]$. A two sample $t$ test was used to assess the difference in urine volume between climates.

\section{Results}

\section{Summary of studies considered for primary analysis}

The 44 studies considered for inclusion in the primary analysis were published from 1981 to 2018 (Tables 3 and 4). Of these, 14 reported findings from Europe [25, 26, 28-30, 46, $50,56,60,66,70,71,81,82]$, seven from the United Kingdom [36, 48, 56, 57, 61, 68, 75], seven from Asia [49, 51, 52, 58, 65, 68, 73], four from North America [55, 64, 69, 76], three from South America [44, 62, 72], three from the Middle East [43, 67, 74], three from Africa [37, 54, 76], and one from Australia [35].

Twenty-five studies reported creatinine excretion $[25,29$, 35-37, 43, 45, 46, 49, 52-54, 58, 61, 63, 64, 67, 69-71, 73, 75, 77, 79, 81], 17 as 24-h excretion $(\mathrm{mmol} / 24 \mathrm{~h}, \mathrm{mg} / 24 \mathrm{~h}$, g/24 h) [29, 35-37, 45, 46, 49, 52-54, 58, 63, 64, 69, 70, $73,81]$, six as a ratio of creatinine to body weight ( $\mathrm{mmol} /$ 
Fig. 2 Flow chart of studies included in analyses

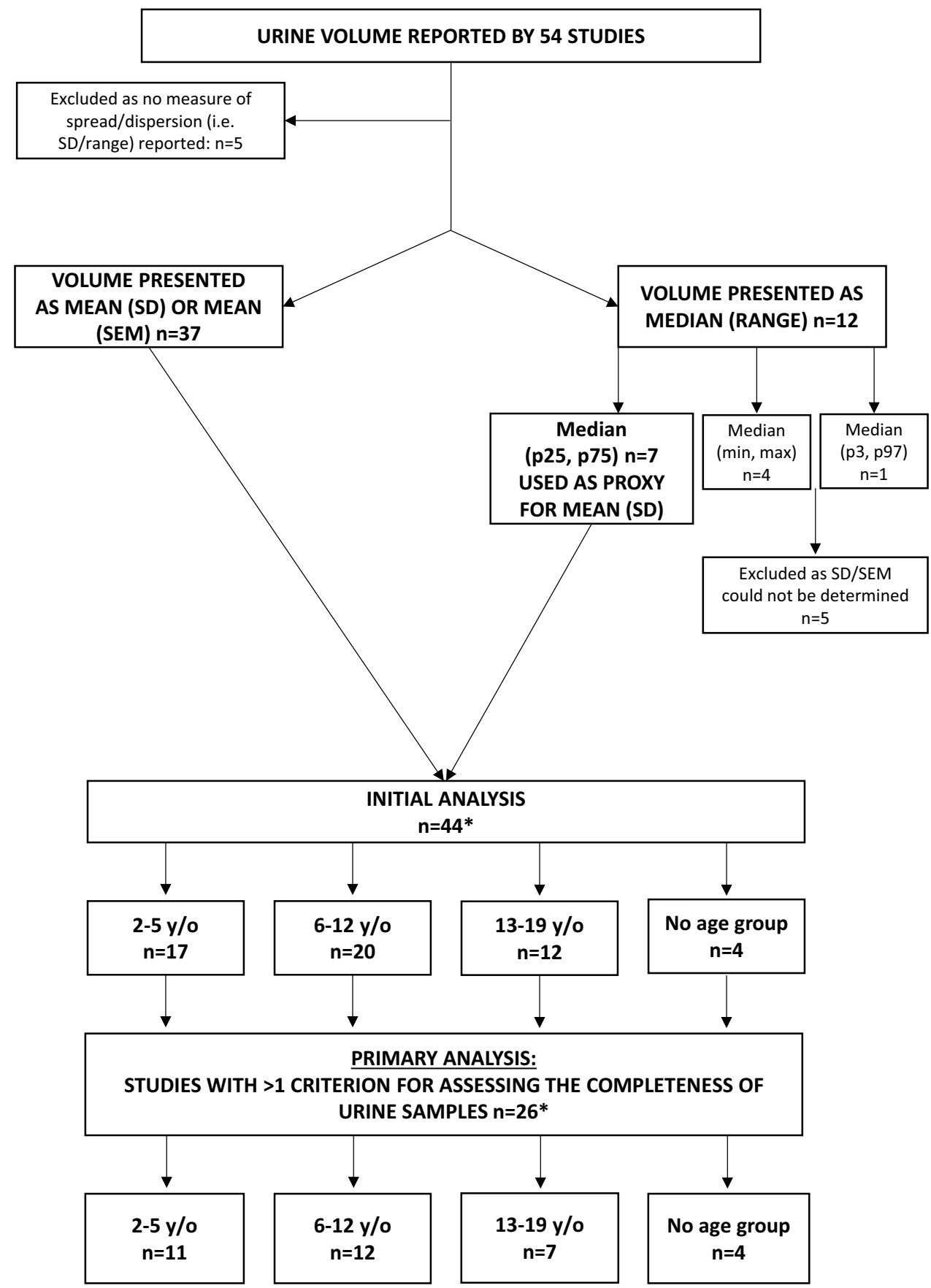

$\mathrm{kg}, \mathrm{mg} / \mathrm{kg})[25,61,67,71,75,77]$ and two as a ratio to urine volume [43, 79].

\section{Quality of studies considered for primary analysis}

The criteria used to evaluate the completeness of the urine samples was inconsistent between studies, 18 studies did not provide any information on criteria used to assess the completeness of the urine samples [44, 45, 47, 49-51, 53, $58,59,62,63,65,68,69,71,72,76,82]$. Of the 26 studies which reported their urine assessment criteria, 21 used creatinine excretion per kilogram of bodyweight $[25,26$, 28-30, 35-37, 43, 46, 52, 54, 61, 64, 66, 67, 70, 73-75, 81], based on established age and gender-specific cutoffs [85]. The remaining five studies relied solely on urine volume $[56,57]$, the number of reported missed collections [48], the excretion of other nutrients (i.e., fluoride) [55], and paraminobenzoic acid (PABA) recovery as a measure of completeness [60]. Across all 26 studies, a total of ten studies utilised urinary volume as an indicator of completeness [35-37, 43, $48,52,56,57,61,67]$, three $[35,37,52]$ used the cut-off of $300 \mathrm{~mL} / 24 \mathrm{~h}$ based on previously published criteria [86], 


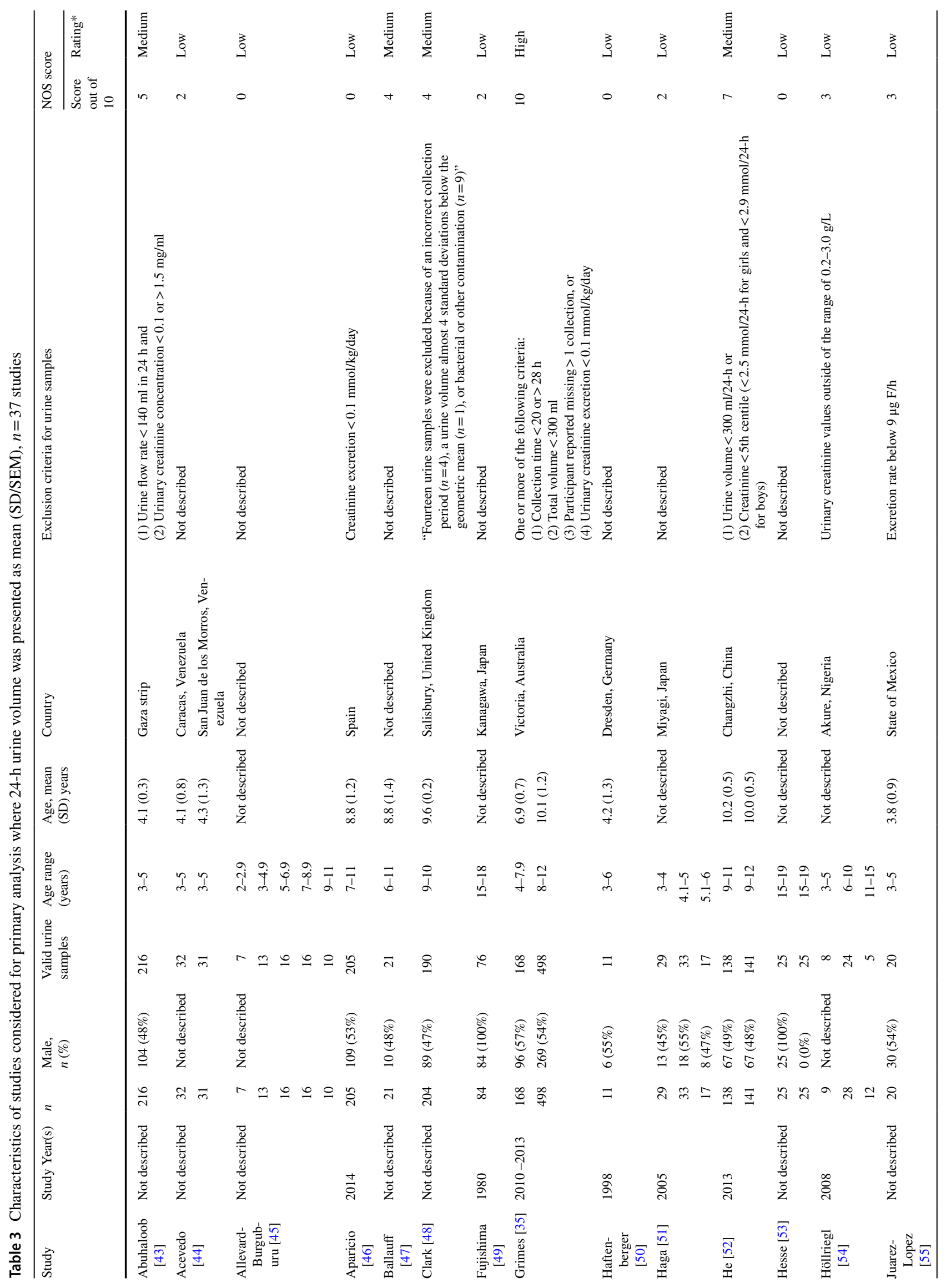




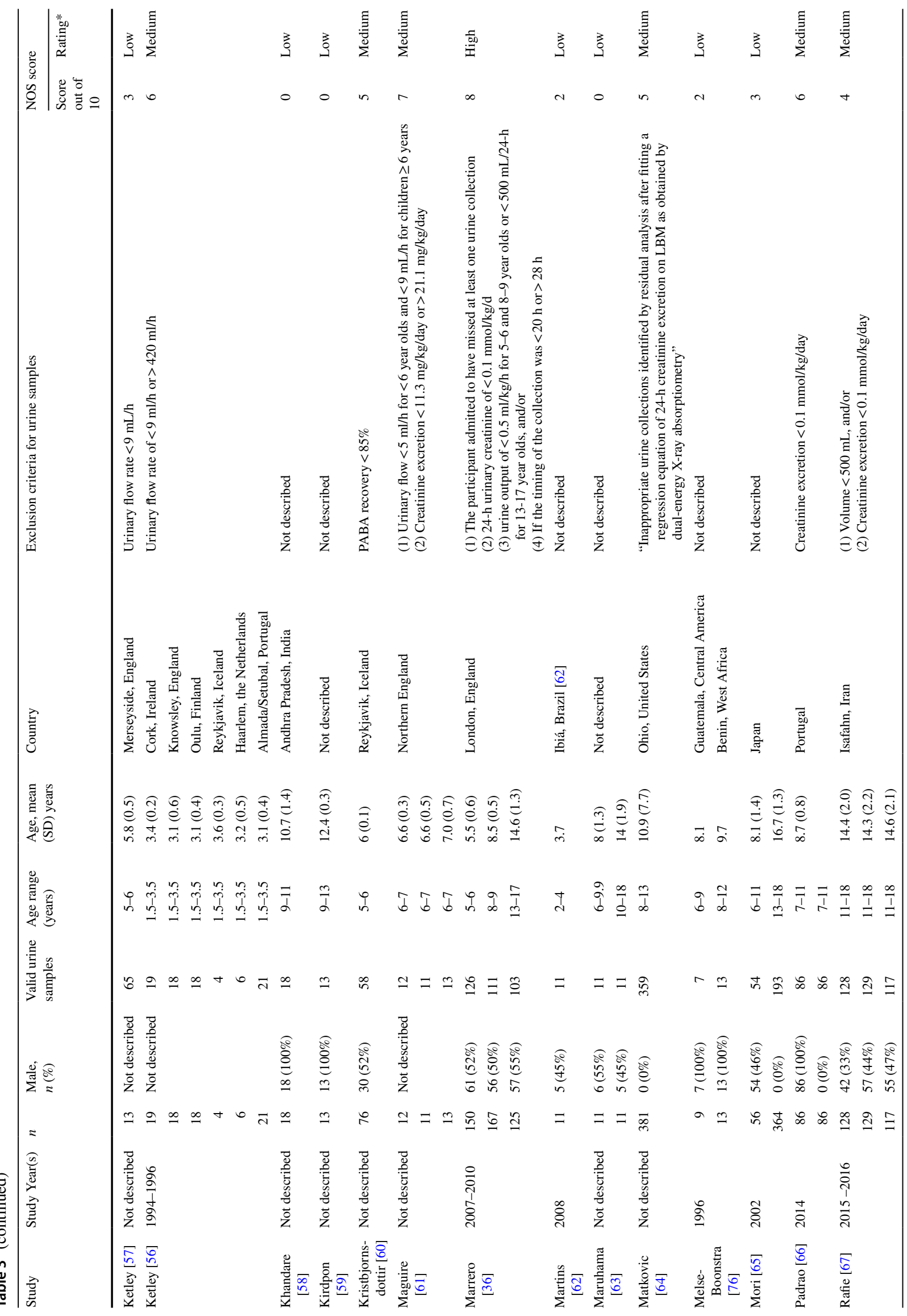




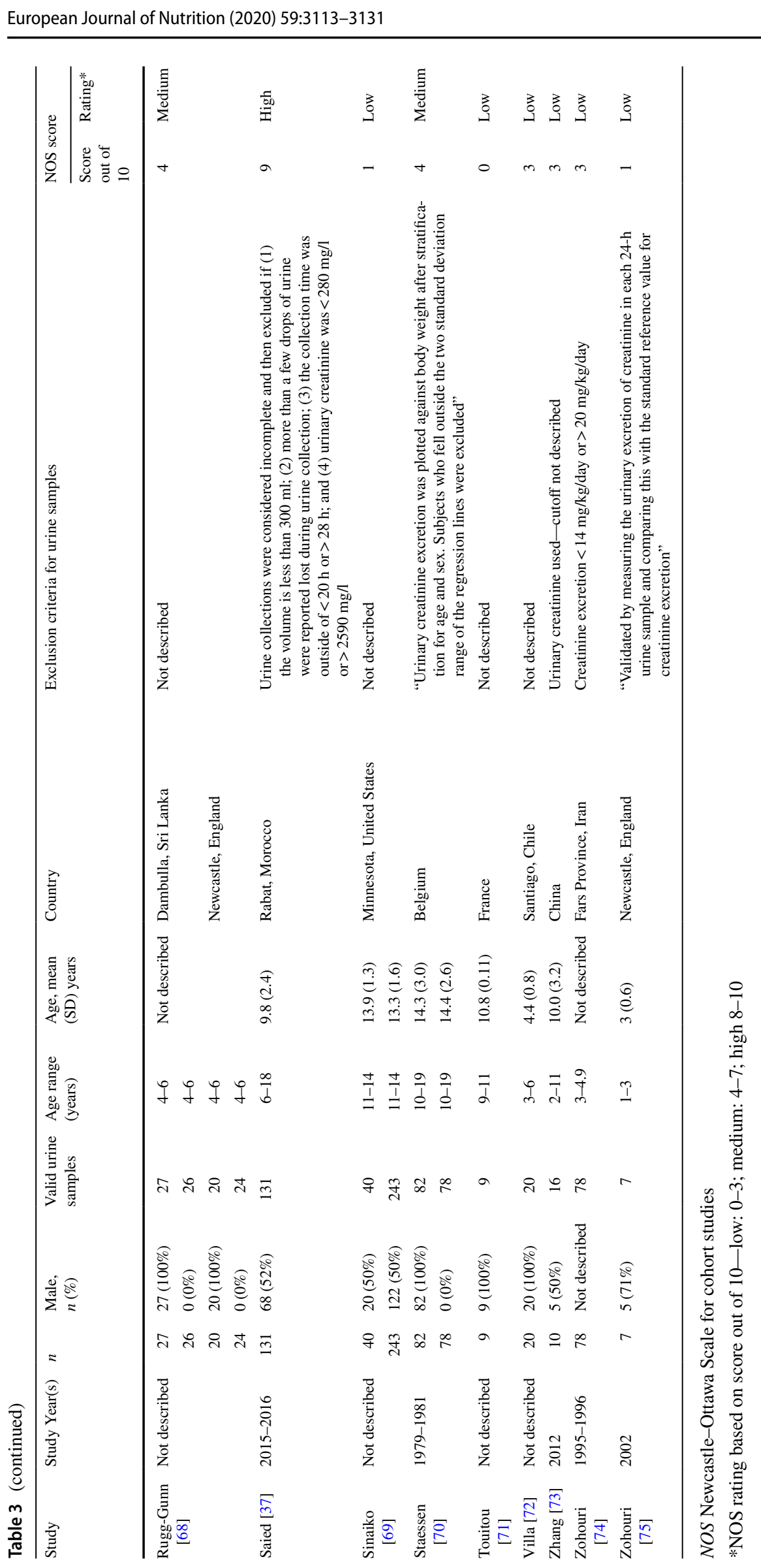

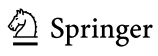




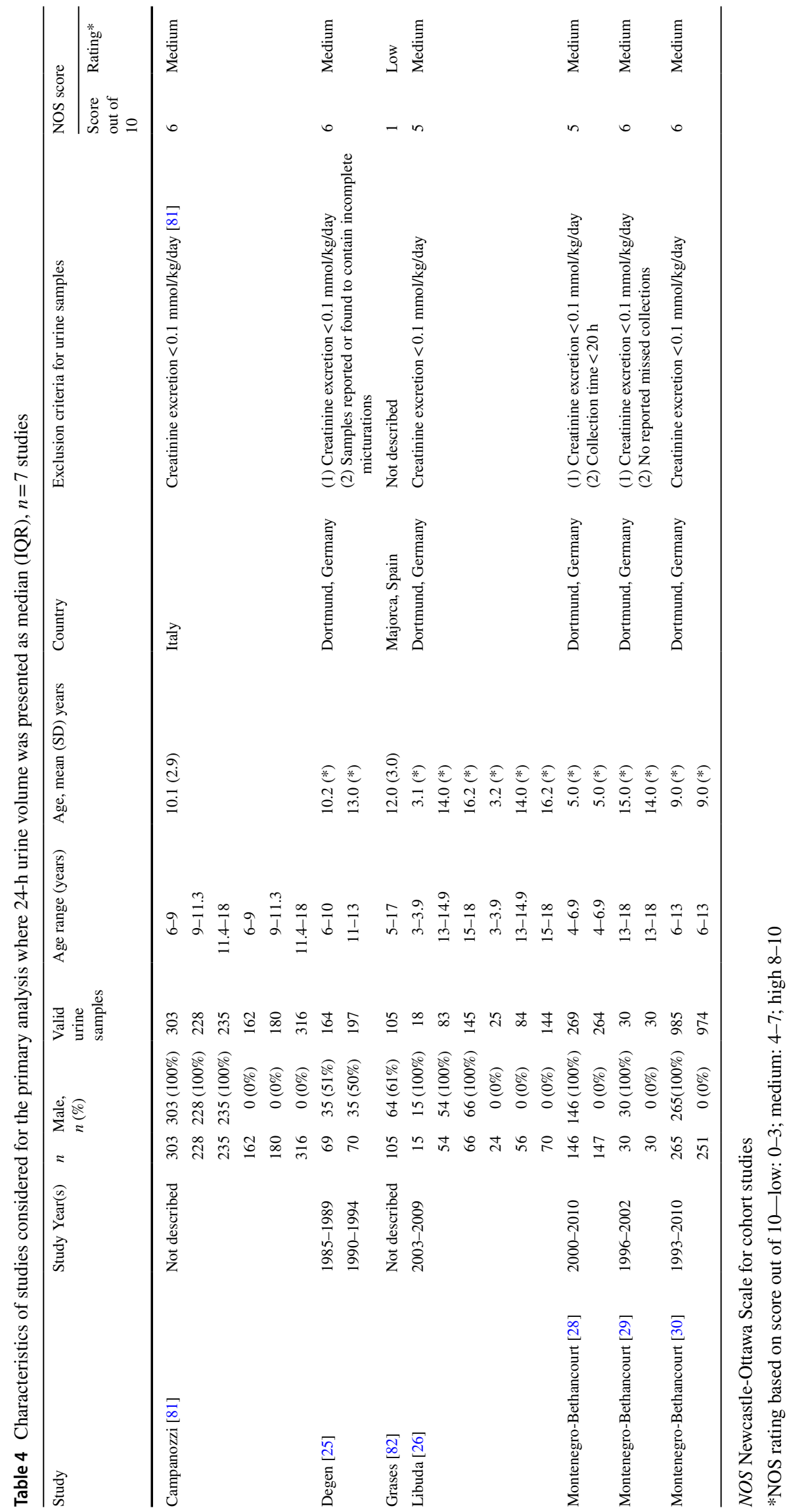


two studies $[56,61]$ utilised the WHO criteria of $<5 \mathrm{~mL} / \mathrm{h}$ and $<9 \mathrm{~mL} / \mathrm{h}$ for $<6$ and $\geq 6$ year olds, respectively, and two studies $[36,67]$ in older children (13-19 years) used the cutoff of $<500 \mathrm{~mL} / 24 \mathrm{~h}$, based on previously published criteria [86]. The cut-offs used by the remaining three studies $[43,48,55]$ were based on the distribution of volume in the sample, enabling the exclusion of extreme outliers (e.g., 4SDs below the geometric mean [48]). Of the 26 studies which reported the urine exclusion criteria, 6 did not report the number of urine samples excluded from the final analysis $[25,54,73-75,82]$.

As a result of the inconsistency in the criteria used to assess the completeness of the urine samples between studies, 23 studies (54\%) scored low on the NOS quality scale [44-46, 49-51, 53-55, 57-59, 62, 63, 65, 69, 71-76, 82] (Tables 3 and 4). Eighteen studies (42\%) were classified as "medium" [25, 26, 28-30, 43, 47, 48, 52, 56, 60, 61, 64, $66-68,70,81]$, and only three studies provided sufficient detail regarding the 24 -h urine collection procedure to be classified as "high" quality [35-37] (Tables 3 and 4).

\section{Initial analysis}

The overall mean urine volume estimate $(95 \% \mathrm{CI})$ for all 44 studies ( $n=7712,9538$ urine samples) was $722(686,758)$ $\mathrm{mL} / 24$-h. Eleven studies reported the results broken down by gender [26, 28-30, 37, 53, 65, 66, 68, 70, 81]. There was no difference in mean urine volume between genders (858.09 (286) $\mathrm{mL} / 24-\mathrm{h}(n=2635,2635$ urine samples) and 818 (240) $\mathrm{mL} / 24-\mathrm{h}$ ( $n=2504,2504$ urine samples), for males and females, respectively, $P=0.7$ ). When broken down by age group, there were more than three times the number of urine collections for 6-12 year olds compared with 2-5 year olds and approximately half the number of samples for the $13-19$ year olds. Sixteen studies reported results for $2-5$ year olds ( $n=1304,1557$ urine samples), 20 for 6-12 year olds $(n=3772,5210$ urine samples) and 12 for 13-19 year olds ( $n=2230,2359$ urine samples). For each of the three age groups, the overall estimate $(95 \% \mathrm{CI})$ was $461(413,509)$ mL/24-h among 2-5 year/olds (Supplemental Fig. 1), 758 (725, 791)mL/24-h for 6-12 year olds (Supplemental Fig. 2) and $1048(973,1123) \mathrm{mL} / 24-\mathrm{h}$ for 13-19 year olds (Supplemental Fig. 3). There was a significant difference in the mean urine volume across the three age groups $(P<0.001)$.

\begin{tabular}{|c|c|c|c|}
\hline Study ID & & ES $(95 \% \mathrm{Cl})$ & $\%$ Weight \\
\hline Abuhaloob_2015 & $\leftarrow$ & $303.00(283.00,323.00)$ & 6.06 \\
\hline Libuda_2012 & & $394.10(281.89,506.31)$ & 5.38 \\
\hline Ketley_2004 & & $440.00(291.04,588.96)$ & 4.94 \\
\hline Juarez-Lopez_2016 & & $455.00(380.06,529.94)$ & 5.75 \\
\hline Zohouri_2000 & & $465.00(426.83,503.17)$ & 5.99 \\
\hline Ketley_2004 & & $474.00(400.71,547.29)$ & 5.76 \\
\hline Ketley_2004 & & $493.00(317.91,668.09)$ & 4.61 \\
\hline Libuda_2012 & & $495.50(356.22,634.78)$ & 5.06 \\
\hline Ketley_2001 & & $506.00(456.89,555.11)$ & 5.93 \\
\hline Ketley_2004 & & $514.00(394.78,633.22)$ & 5.30 \\
\hline Zohouri_2006 & & $523.00(328.17,717.83)$ & 4.36 \\
\hline Höllriegl_2011 & & $597.80(558.09,637.51)$ & 5.98 \\
\hline Montenegro-Bethancourt_2013 & & $605.00(564.37,645.63)$ & 5.98 \\
\hline Montenegro-Bethancourt_2013 & & $610.00(572.00,648.00)$ & 5.99 \\
\hline Ketley_2004 & & $632.00(513.27,750.73)$ & 5.31 \\
\hline Kristbjornsdottir_2012 & & $648.00(574.91,721.09)$ & 5.76 \\
\hline Marrero_2014 & & $650.00(585.85,714.15)$ & 5.83 \\
\hline Ketley_2004 & & $717.00(676.80,757.20)$ & 5.98 \\
\hline Overall $(1$-squared $=97.2 \%, p=0.000)$ & & $530.76(454.21,607.32)$ & 100.00 \\
\hline NOTE: Weights are from random effects analysis & & & \\
\hline
\end{tabular}

Fig. 3 Forest plot of studies assessing 24-h urine volumes of 2-5 year olds with $>1$ urine assessment criterion $(n=1084)$ 


\begin{tabular}{|c|c|c|}
\hline Study ID & ES $(95 \% \mathrm{Cl})$ & $\%$ Weight \\
\hline Maguire_2013 & $547.20(374.75,719.65)$ & 2.53 \\
\hline Maguire_2013 & $590.40(471.26,709.54)$ & 3.58 \\
\hline Clark_1996 & $653.00(593.56,712.44)$ & 5.02 \\
\hline Degen_2011 & $660.00(596.64,723.36)$ & 4.93 \\
\hline Maguire_2013 & $672.00(467.17,876.83)$ & 2.06 \\
\hline Grimes_2016 & $722.00(676.64,767.36)$ & 5.31 \\
\hline Montenegro-Bethancourt_2015b & $730.00(704.27,755.73)$ & 5.62 \\
\hline Montenegro-Bethancourt_2015b & $735.00(707.74,762.26)$ & 5.60 \\
\hline Matkovic_1995 & $735.88(702.19,769.57)$ & 5.51 \\
\hline Padrao_2016 & $739.00(670.73,807.27)$ & 4.81 \\
\hline Campanozzi_2015 & $750.00(696.10,803.90)$ & 5.14 \\
\hline Padrao_2016 & $763.00(696.21,829.79)$ & 4.85 \\
\hline Campanozzi_2015 & $800.00(754.96,845.04)$ & 5.32 \\
\hline Marrero_2014 & $802.00(722.67,881.33)$ & 4.55 \\
\hline Campanozzi_2015 & $850.00(769.65,930.35)$ & 4.52 \\
\hline $\mathrm{He} \_2015$ & $862.00(787.52,936.48)$ & 4.66 \\
\hline Grimes_2016 & $866.00(827.53,904.47)$ & 5.44 \\
\hline $\mathrm{He} \_2015$ & $867.00(794.48,939.52)$ & 4.71 \\
\hline Höllriegl_2011 & $868.40(854.03,882.77)$ & 5.73 \\
\hline Aparicio_2015 & $870.00(828.10,911.90)$ & 5.37 \\
\hline Campanozzi_2015 & $900.00(828.61,971.39)$ & 4.74 \\
\hline Overall (I-squared $=92.6 \%, p=0.000)$ & $771.05(734.47,807.62)$ & 100.00 \\
\hline NOTE: Weights are from random effects analysis & & \\
\hline
\end{tabular}

Fig. 4 Forest plot of studies assessing 24-h urine volumes of 6-12 year olds with $>1$ urine assessment criterion $(n=3628)$

\section{Primary analysis limited to studies with $>1$ urine completeness assessment criterion}

Twenty-six studies reported $\geq 1$ criterion for assessing the completeness of the urine samples $(n=6322,8331$ urine samples) [25, 26, 28-30, 35-37, 43, 46, 48, 55-57, 60, 61, $64,66,67,70,73-75,81]$. The overall urine volume estimate $(95 \% \mathrm{CI})$ for these studies was $773(654,893) \mathrm{mL} / 24$ h [median (IQR) 737 (284) mL/24-h]. When studies were assessed by climate ("warm" climate (2 studies) [54, 55] versus "cold" climate (25 studies) [25, 26, 28-30, 35-37, 43, 46, 48, 52, 56, 57, 60, 61, 64, 66, 67, 70, 73-75, 81, $82])$ there was no difference in mean $(95 \%$ CI) $24-\mathrm{h}$ urine volume: "warm" hot $788(244,1332) \mathrm{mL} / 24-\mathrm{h}$ vs "cold" 779 $(713,845) \mathrm{mL} / 24-\mathrm{h}, P=0.96$.

When broken down by age group, 11 studies reported results for 2-5 year olds ( $n=987,1240$ urine samples) [26, 28, 36, 43, 54-57, 60, 74, 75], 12 for 6-12 year olds ( $n=3596,5038$ urine samples) $[25,30,35,36,46,48,52$, $54,61,64,66,81]$ and seven for 13-19 year olds $(n=1438$, 1746 urine samples) $[25,26,29,36,54,67,81]$. The overall estimate $(95 \% \mathrm{CI})$ for each of the three age groups were 531 (454, 607) (Fig. 3), 771 (734, 808) (Fig. 4), and 1067 (855,
1279) (Fig. 5) mL/24-h, respectively. There was a significant difference in the mean urine volume across the three age groups $(P<0.001)$. Posthoc analyses revealed that children in the oldest age group had a $28 \%$ higher 24 -h urine volume compared to those aged 6-12 years (1067 vs. $771 \mathrm{~mL} / 24-$ h, $P<0.001)$ and approximately $50 \%$ higher urine volume compared to those aged 2-5 years (1067 vs. $531 \mathrm{~mL} / 24-\mathrm{h}$, $P<0.001)$. Similarly, those aged $6-12$ had a $31 \%$ higher volume compared to $2-5$ year olds (771 vs. $531 \mathrm{~mL} / 24 \mathrm{~h}$, $P<0.001)$. There was significant between study heterogeneity across all three age groups (2-5 years/olds: $I^{2}=97.2 \%$, $P<0.001$, Fig. 3; 6-12 years/olds: $I^{2}=92.6 \%, P<0.001$, Fig. 4; 13-19 years/olds: $I^{2}=99.7 \%, P<0.001$, Fig. 5).

When comparing the mean urine volume between those studies which reported at least one criterion for assessing the completeness of urine samples and those which reported none, the only difference in mean urine volume was amongst the 2-5 year old age group. In this age group, the mean urine volume in the initial analysis (i.e., all studies were included) was $27 \%$ lower compared to the primary analysis (i.e., when the analysis was limited to only those studies with $\geq 1$ criterion for assessing the completeness of urine samples (386 vs. $529 \mathrm{~mL} / 24-\mathrm{h}, P=0.001)$. 


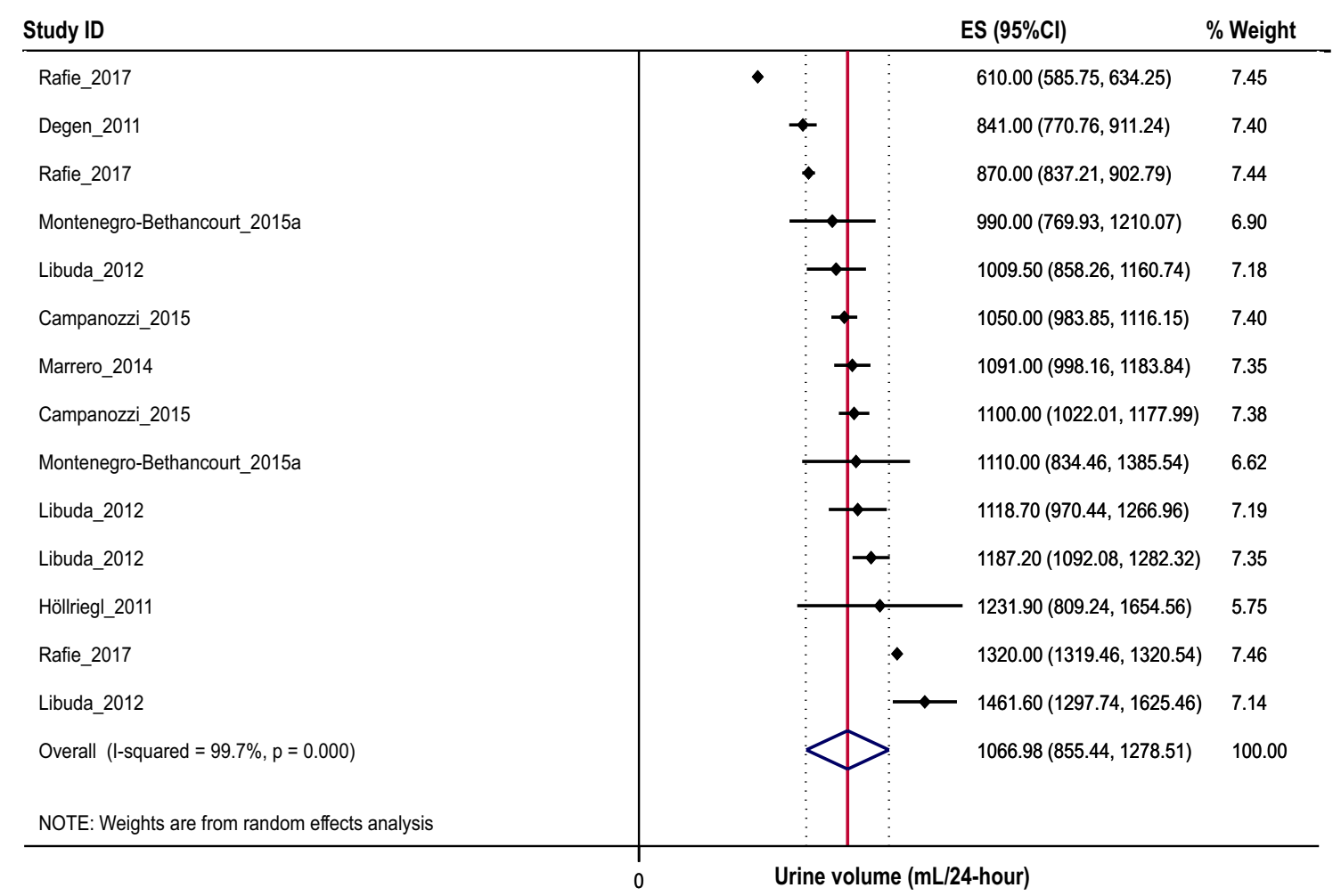

Fig. 5 Forest plot of studies assessing 24-h urine volumes of 13-19 year olds with $>1$ urine assessment criterion $(n=1438)$

Of the 26 studies with at least one criterion for assessing the completeness of the urine samples, only twelve [25, 28, $29,35-37,43,48,52,55,61,64]$ had at least two urine criteria ( $n=2867,3191$ urine samples). In these twelve studies, the mean $(95 \% \mathrm{CI}$ urine volume estimate was $742(639,844)$ $\mathrm{mL} / 24-\mathrm{h}$. There was no difference in the mean $(95 \% \mathrm{CI})$ urine volume estimate of these studies, compared to those with only one assessment criterion $[n=15,798(664,932)$ $\mathrm{mL} / 24-\mathrm{h}, P=0.33]$ or those with none $[n=18,635$ (577, 692) $\mathrm{mL} / 24$-hs $P=0.28]$.

For those studies with at least one criterion for assessing the completeness of urine collections there was less variation in daily urinary volume for those 6-12 years compared to 2-5 and 13-19 year olds. The co-efficient of variation (CV) for 6-12 year olds was $13 \%$ compared to $20 \%$ in $2-5$ and 13-19 year olds. There was no difference in CVs between those studies with no reported criterion for completeness and those reporting at least one criterion (overall CV: $32 \%$ vs. $27 \%$ ). In contrast, the $\mathrm{CV}$ for those aged between 13 and 19 years was reduced to $12 \%$ in those studies utilising least two criteria for assessing completeness of urine collection, compared with $20 \%$ for those studies utilising only one criterion for assessment for completeness.

\section{Discussion}

This is the first study to systematically review the 24-h urine volume of children and adolescents. The overall 24 -h overall urine volume estimate (95\% CI) of 2-19 year olds was $778(661,895) \mathrm{mL} / 24-\mathrm{h}$ urine. As expected, older children had higher urine volumes with children in the oldest age group (13-19 years) having a $28 \%$ higher 24 -h urine volume compared to those aged $6-12$ years (1067 vs. $771 \mathrm{~mL} / 24-$ h, $P<0.001)$ and approximately $50 \%$ higher urine volume compared to those aged $2-5$ years $(1067$ vs. $531 \mathrm{~mL} / 24-\mathrm{h}$, $P<0.001)$.

As approximately $90 \%$ of ingested iodine is excreted in the urine within 24-48 h [87], current recommendations for assessing the severity of iodine deficiency within a population are based on the measurement of urinary iodine concentration (UIC), expressed as $\mu$ g iodine per liter of urine, in random 'spot' urine samples collected from school-aged children (i.e., 6-12 years [6]). Although these recommendations were originally based on the observation that goiter prevalence was $<10 \%$ in populations of children and adults where the average daily iodine intakes were $>100 \mu \mathrm{g}$, later iterations extrapolated this value to represent a concentration, expressed as $\mu \mathrm{g} / \mathrm{L}$ [4]. However, results from this analysis indicate that the average 24 -h urine volume of schoolaged children, the group commonly recommended for use 
in population iodine monitoring, is not $1 \mathrm{~L}$ and is closer to $0.8 \mathrm{~L}$. Therefore, a median spot urine concentration of $100 \mu \mathrm{g} / \mathrm{L}$ (extrapolated to a median iodine intake of $100 \mu \mathrm{g} /$ day) would overestimate iodine intake by approximately $30 \mu \mathrm{g} /$ day.

Iodine excretion from spot urine samples is most often expressed as a concentration or as a ratio to creatinine excretion (I/Cr, $\mu$ g iodine/g creatinine) $[29,88,89]$. The use of $\mathrm{I} /$ $\mathrm{Cr}$ to estimate daily iodine intake is believed to provide an accurate estimate of daily iodine excretion from spot urine samples as creatinine, an endogenous indicator of lean body mass is relatively constant from day to day in healthy adult populations $[32,90]$. Whilst this is true in adults, estimating expected creatinine excretion values for children can be difficult as creatinine excretion can be affected by muscle mass, age, gender, ethnicity and onset of puberty [91]. Some equations for estimating daily creatinine excretion are able to account for these factors, whilst others provide a more crude estimate of daily creatinine excretion [92].

In addition, whilst the variation in individual iodine excretion between days is largely dependant on the iodine content of the diet, iodine excretion has also been found to vary over the course of the day in individuals $[29,88$, 89, 92-97]. One study conducted in 42 adults and children (aged 4-60 years) found that urinary iodine excretion varied significantly by the timing of collection $(P<0.001)$, with lowest levels occurring in the morning and peaks observed following meals [98]. A recent systematic review of studies comparing spot and 24-h urine samples for estimating the iodine intakes of a population concluded that there is currently not enough evidence to determine whether iodine intake determined from spot urine samples provides an accurate reflection of daily iodine intake, as measured using 24-h urine samples [99].

Furthermore, whilst the WHO recommendation for assessing the iodine status of populations are primarily meant for use in school-aged children, and were derived primarily on data based on goiter prevalence estimates in school-aged children, they have also been used to define the iodine status of adult populations [100-103]. Issues concerning different urinary volume outputs among different subsets of the population and implications for iodine nutrition assessment have been previously identified by Zimmerman and Andersson [104]. They highlighted that as the urine volume of adults is closer to $1.5 \mathrm{~L}$ [27, 105], the use of the median UIC determined using spot urine samples could result in the underestimation of the iodine intakes of adult individuals within the population [104]. This was demonstrated in a recent study in 301 adults (18-64 years) from New Zealand, which compared median UIC from 24-h urine samples to the WHO criteria, both with and without adjustment for total urine volume [101]. This sample of adults was classified as iodine deficient using the WHO criteria, based on a median UIC of $73 \mu \mathrm{g} / \mathrm{L}$. However, the measured 24-h UIE, which accounts for urine volume and averaged $2 \mathrm{~L}$ was closer to $127 \mu \mathrm{g} /$ day [101]. This value is in excess of the $100 \mu \mathrm{g} / \mathrm{day}$ originally associated with reduced goiter prevalence [8] and would indicate that the iodine intakes of this group of adults may be sufficient [8]. The New Zealand study demonstrates the potential impact of not accounting for the daily urine volume may have on the assessment of iodine deficiency in populations when UIC determined from spot urine samples is used as a surrogate index of iodine intake.

\section{Strengths and limitations}

We observed considerable between-study heterogeneity across all three age groups in the primary analysis limited to studies with $>1$ indicator of urine completeness. For all three age groups the age range of participants included within each group varied considerably. For example, within the 2-5 year age group one study consisted of participants aged 1.5-3.5 years [56] whilst another consisted of participants aged 3-6 years [72]. Differences in both the age range of participants as well as the number of participants between studies, along with season of assessment and overall diet composition may have contributed to the observed heterogeneity.

In addition, there were considerable variations in the mean/median reported urine volumes, even within the three age groups, particularly for $2-5$ year olds. This may represent the practical difficulties in obtaining accurate $24 \mathrm{~h}$ urine collections in young children, however, it is important to note that the included studies did not consistently report their 24-h urine collection protocol, nor the indicators used to assess the completeness of included urine samples. Of the 44 studies reviewed, 17 studies (40\%) did not report at least one indicator for completeness of the 24-h urine samples. The only difference in the mean urine volume estimate between the total sample and those studies with $\geq 1$ indicator for completeness of urine samples, was seen among the youngest age group (2-5 years) where average urine volume was $143 \mathrm{ml} / 24$-h less in the studies which reported no criterion for assessing the completeness of included urine samples. A recent systematic review of methods for assessing the completeness of 24-h urine collections in adults and children (15-89 years) concluded that that the use of two or more indicators for assessing urine completeness increases the likelihood of detecting incomplete samples, thus increasing the validity of the results [33]. Our findings are contrary to this in that we found no difference in urine volume among those studies that had at least two urine assessment criteria, compared to those with only one. In the present review, only 12 studies utilised more than one criterion $[25,28,29$, $35-37,43,48,52,55,61,64]$, and there was no difference 
in mean 24-h urine volume estimated from these studies compared to the overall estimate from all 44 studies. However, there was less variation in daily urinary volume in the 6-12 year group (CV 13\%). Overall there seemed to be little impact on urine volume variation of including a number of criteria for completeness of $24 \mathrm{~h}$ urine collection, except for the 13-19 year age group where studies that included at least two criteria for completeness appeared to have less variation (CV 16\%) compared with studies with only one criterion (CV 20\%).

In this analysis, only two studies collected 24-h urine samples from countries classified as having a "warm" climate", compared to 25 studies from a "cold" climate. There is also considerable within and between person daily variability in iodine excretion $[92,95,96,98,106,107]$. One study conducted in 42 adults and children (aged 4-60 years) observed that the lowest level of iodine excretion occurred in the morning with peaks observed following meals [98]. Furthermore, a study in adults noted that UIC determined from a fasting spot urine samples was $10 \%$ lower than that determined in a non-fasting spot urine sample [96]. Although this variation has yet to be assessed in children, this study indicates that the timing of a spot urine sample used to estimate the iodine intake of a population may also have a significant impact on the overall assessment of iodine nutrition. Therefore, it is clear that a number of factors need to be considered when making population estimates of iodine intake using spot urine collections across the age range from early childhood to adolescence.

\section{Conclusion}

This is the first systematic review to report the average 24-h urine volume of children and adolescents from 44 studies representing 7712 individuals with 3772 individuals within the 6-12 year old age group, which included at least one criterion for completeness of urine collection. The average urine volume in this group was $771 \mathrm{~mL}$, which is less than $1 \mathrm{~L}$. This has implications when extrapolating median iodine values $(\mu \mathrm{g} / \mathrm{L})$ from spot urine samples to daily iodine intakes of 6-12 year old children as the average 24 -h urine volume is less than $1 \mathrm{~L}$, potentially resulting in an overestimate of dietary iodine intake in the order of $30 \%$. Future studies employing spot urine samples to determine the iodine status of children and adolescents should consider undertaking 24-h urine collections in a subset of participants, to determine total urine volume and iodine excretion. This will allow the assessment of the accuracy of utilizing UIC as a proxy measure of daily iodine intake and potentially prevent the misclassification of iodine intakes in the population.
Acknowledgements CAN, LJR and SAS created the study concept and design. KB and MW performed the literature search and study selection. KB conducted data extraction and data analysis and wrote the manuscript. All of the authors were involved in and contributed to analysis and interpretation of data and the critical revision of the final manuscript. The authors declare that they have no conflict of interest.

Funding At the time of this work KB was funded by an Australian Postgraduate Award Scholarship (Award ID: 0000019017).

Open Access This article is distributed under the terms of the Creative Commons Attribution 4.0 International License (http://creativeco mmons.org/licenses/by/4.0/), which permits unrestricted use, distribution, and reproduction in any medium, provided you give appropriate credit to the original author(s) and the source, provide a link to the Creative Commons license, and indicate if changes were made.

\section{References}

1. Gordon RC, Rose MC, Skeaff SA, Gray AR, Morgan KM, Ruffman $T$ (2009) Iodine supplementation improves cognition in mildly iodine-deficient children. Am J Clin Nutr 90(5):12641271. https://doi.org/10.3945/ajcn.2009.28145

2. Zimmermann MB, Connolly K, Bozo M, Bridson J, Rohner F, Grimci L (2006) Iodine supplementation improves cognition in iodine-deficient schoolchildren in Albania: a randomized, controlled, double-blind study. Am J Clin Nutr 83(1):108-114

3. World Health Organization, United Nations Children's Fund, International Council for the Control of Iodine Deficiency Disorders (1990) A practical guide to the correction of iodine deficiency. International Council for the Control of Iodine Deficiency Disorders, Wageningen

4. World Health Organization, United Nations Children's Fund, International Council for the Control of Iodine Deficiency Disorders (1993) Indicators for assessing iodine deficiency disorders and their control programmes. In: Report of a joint WHO/ UNICEF/ICCIDD consultation, Geneva, Switzerland, 3-5 November 1992. World Health Organisation, Geneva

5. World Health Organization, United Nations Children's Fund, International Council for the Control of Iodine Deficiency Disorders (2001) Assessment of iodine deficiency disorders and monitoring their elimination: a guide for programme managers, 2nd edn. World Health Organisation, Geneva

6. World Health Organization, United Nations Children's Fund, International Council for the Control of Iodine Deficiency Disorders (2007) Assessment of iodine deficiency disorders and monitoring their elimination: a guide for programme managers, 3rd edn. World Health Organisation, Geneva

7. World Health Organization (2013) Urinary iodine concentrations for determining iodine status in populations. World Health Organistion. http://www.who.int/vmnis/indicators/urinaryiodine/ en/. Accessed 26 March 2014

8. Ascoli W, Arroyave G (1970) Epidemiologia el bocio endémico en Centro América. Relación entre prevalencia y excreción urinaria de yodo [Epidemiology of endemic goiter in Central America. Association between prevalence and urinary iodine excretion]. Arch Latinoam Nutr 20:309-320

9. World Health Organization (2004) Iodine status worldwide: WHO global database on iodine deficiency, vol 26. World Health Organization, Geneva

10. Andersson M, Takkouche B, Egli I, Allen HE, De Benoist B (2007) Current global iodine status and progress over the last 
decade towards the elimination of iodine deficiency. Bull WHO 85(5):518-525

11. de Benoist B, McLean E, Andersson M, Rogers L (2008) Iodine deficiency in 2007: global progress since 2003. Food Nutr Bull 29(3):195-202

12. Andersson M, Karumbunathan V, Zimmermann MB (2012) Global iodine status in 2011 and trends over the past decade. $\mathbf{J}$ Nutr 142(4):744-750. https://doi.org/10.3945/jn.111.149393

13. Zimmermann MB (2013) Iodine deficiency and excess in children: worldwide status in 2013. Endocr Pract 19(5):839-846. https://doi.org/10.4158/EP13180.RA

14. Pearce EN, Andersson M, Zimmermann MB (2013) Global iodine nutrition: where do we stand in 2013? Thyroid 23(5):523528. https://doi.org/10.1089/thy.2013.0128

15. Moher D, Shamseer L, Clarke M, Ghersi D, Liberati A, Petticrew M, Shekelle P, Stewart LA (2015) Preferred reporting items for systematic review and meta-analysis protocols (PRISMA-P) 2015 statement. Syst Rev 4:1. https://doi.org/10.1186/2046-4053-4-1

16. Moher D, Liberati A, Tetzlaff J, Altman DG, Group P (2009) Preferred reporting items for systematic reviews and meta-analyses: the PRISMA statement. BMJ 339:b2535. https://doi.org/10.1136/ bmj.b2535

17. Kroke A, Manz F, Kersting M, Remer T, Sichert-Hellert W, Alexy U, Lentze MJ (2004) The DONALD study. History, current status and future perspectives. Eur J Nutr 43(1):45-54. https ://doi.org/10.1007/s00394-004-0445-7

18. Bokhof B, Günther ALB, Berg-Beckhoff G, Kroke A, Buyken AE (2010) Validation of protein intake assessed from weighed dietary records against protein estimated from $24 \mathrm{~h}$ urine samples in children, adolescents and young adults participating in the Dortmund Nutritional and Longitudinally Designed (DONALD) Study. Public Health Nutr 13(6):826-834. https://doi. org/10.1017/S136898000999317X

19. Dimitriou T, Huesemann S, Neubert A, Remer T (2001) Measurements of urinary leptin and capillary leptin: alternative tools for the assessment of the leptin status? Horm Res 56(3-4):93-97

20. Ebner A, Manz F (2002) Sex difference of urinary osmolality in German children. Am J Nephrol 22(4):352-355

21. Esche J, Johner S, Shi L, Schonau E, Remer T (2016) Urinary citrate, an index of acid-base status, predicts bone strength in youths and fracture risk in adult females. J Clin Endocrinol Metab 101(12):4914-4921. https://doi.org/10.1210/jc.2016-2677

22. Penczynski KJ, Krupp D, Bring A, Bolzenius K, Remer T, Buyken AE (2015) Relative validation of 24-h urinary hippuric acid excretion as a biomarker for dietary flavonoid intake from fruit and vegetables in healthy adolescents. Eur J Nutr 56:757-766

23. Krupp D, Doberstein N, Shi L, Remer T (2012) Hippuric acid in 24-h urine collections is a potential biomarker for fruit and vegetable consumption in healthy children and adolescents. $J$ Nutr 142(7):1314-1320. https://doi.org/10.3945/jn.112.159319

24. Remer T, Shi L, Buyken AE, Maser-Gluth C, Hartmann MF, Wudy SA (2010) Prepubertal adrenarchal androgens and animal protein intake independently and differentially influence pubertal timing. J Clin Endocrinol Metab 95(6):3002-3009. https://doi. org/10.1210/jc.2009-2583

25. Degen GH, Blaszkewicz M, Shi L, Buyken AE, Remer T (2011) Urinary isoflavone phytoestrogens in German children and adolescents-a longitudinal examination in the DONALD cohort. Mol Nutr Food Res 55(3):359-367. https://doi.org/10.1002/ mnfr.201000325

26. Libuda L, Kersting M, Alexy U (2012) Consumption of dietary salt measured by urinary sodium excretion and its association with body weight status in healthy children and adolescents. Public Health Nutr 15(3):433-441. https://doi.org/10.1017/S1368 980011002138
27. Manz F, Johner SA, Wentz A, Boeing H, Remer T (2012) Water balance throughout the adult life span in a German population. $\mathrm{Br}$ J Nutr 107(11):1673-1681. https://doi.org/10.1017/S000711451 1004776

28. Montenegro-Bethancourt G, Johner SA, Remer T (2013) Contribution of fruit and vegetable intake to hydration status in schoolchildren. Am J Clin Nutr 98(4):1103-1112. https://doi. org/10.3945/ajcn.112.051490

29. Montenegro-Bethancourt G, Johner SA, Stehle P, Neubert A, Remer T (2015) Iodine status assessment in children: spot urine iodine concentration reasonably reflects true twenty-fourhour iodine excretion only when scaled to creatinine. Thyroid 25(6):688-697. https://doi.org/10.1089/thy.2015.0006

30. Montenegro-Bethancourt G, Johner SA, Stehle P, Remer T (2015) Dietary ratio of animal:plant protein is associated with 24-h urinary iodine excretion in healthy school children. Br J Nutr 114(1):24-33. https://doi.org/10.1017/S00071145150015 67

31. Cogswell ME, Maalouf J, Elliott P, Loria CM, Patel S, Bowman BA (2015) Use of urine biomarkers to assess sodium intake: challenges and opportunities. Annu Rev Nutr 35(349-387):333p. https://doi.org/10.1146/annurev-nutr-071714-034322

32. Bingham SA, Cummings JH (1985) The use of creatinine output as a check on the completeness of 24-h urine collections. Hum Nutr Clin Nutr 39(5):343-353

33. John KA, Cogswell ME, Campbell NR, Nowson CA, Legetic B, Hennis AJM, Patel SM (2016) Accuracy and usefulness of select methods for assessing complete collection of 24-h urine: a systematic review. J Clin Hypertens 18(5):456-467. https://doi. org/10.1111/jch. 12763

34. Wells GA, Shea B, O'Connell D, Peterson J, Welch V, Losos M, Tugwell P (1999) The Newcastle-Ottawa Scale (NOS) for assessing the quality of nonrandomised studies in meta-analyses. http://www.ohri.ca/programs/clinical_epidemiology/oxford.asp. Accessed 2 Aug 2016

35. Grimes CA, Riddell LJ, Campbell KJ, He FJ, Nowson CA (2016) 24-h urinary sodium excretion is associated with obesity in a cross-sectional sample of Australian schoolchildren. Br J Nutr 115(6):1071-1079. https://doi.org/10.1017/S00071145150052 43

36. Marrero NM, He FJ, Whincup P, Macgregor GA (2014) Salt intake of children and adolescents in South London: consumption levels and dietary sources. Hypertension 63(5):1026-1032. https ://doi.org/10.1161/HYPERTENSIONAHA.113.02264

37. Saeid N, Elmzibri M, Hamrani A, Latifa Q, Belghiti H, El Berri $\mathrm{H}$, Benjeddou K, Bouziani A, Benkirane H, Taboz Y, Elhamdouchi A, El Kari K, Aguenaou H (2018) Assessment of sodium and potassium intakes in children aged 6 to 18 years by $24 \mathrm{~h}$ urinary excretion in city of Rabat, Morocco. J Nutr Metab 1:8. https://doi.org/10.1155/2018/8687192

38. Borawski KM, Sur RL, Miller OF, Pak CYC, Preminger GM, Kolon TF (2008) Urinary reference values for stone risk factors in children. J Urol 179(1):290-294

39. Ajayi OA, Adeyemi IA, Osifo BOA (1977) The urinary excretion of riboflavin among Nigerian teenagers. Ecol Food Nutr $6(1): 49-52$

40. M'Buyamba-Kabangu JR, Fagard R, Lijnen P, Mbuy WA, Mbuy R, Staessen J, Amery A (1986) Blood pressure and urinary cations in urban Bantu of Zaire. Am J Epidemiol 124(6):957-968

41. Omid N, Maguire A, O'Hare WT, Zohoori FV (2017) Total daily fluoride intake and fractional urinary fluoride excretion in 4- to 6-year-old children living in a fluoridated area: weekly variation? Commun Dent Oral Epidemiol 45(1):12-19. https://doi. org/10.1111/cdoe. 12254 
42. Vanderas AP, Papagiannoulis L (1995) Urinary catecholamine levels in children with and without a history of dentofacial injuries. Endod Dent Traumatol 11(5):205-209

43. Abuhaloob L, Maguire A, Moynihan P (2015) Fractional urinary fluoride excretion (FUFE) of 3-4 year children in the gaza strip. Community Dent Health 32(1):8-15

44. Acevedo AM, Febres-Cordero C, Feldman S, Arasme MA, Pedauga DF, Gonzalez H, Rojas-Sanchez F (2007) Urinary fluoride excretion in children aged 3 to 5 years exposed to fluoridated salt at 60 to $90 \mathrm{mgF} / \mathrm{Kg}$ in two Venezuelan cities. A pilot study. Acta Odontol Latinoam 20(1):9-16

45. Allevard-Burguburu AM, Geelen G, Sempore B, Louis F, Legros JJ, Gharib C (1981) Urinary excretion of immunoreactive vasopressin in prepubertal children. Lack of correlation with urinary excretion of immunoreactive neurophysins. Eur J Pediatr 137(3):291-294

46. Aparicio A, Rodriguez-Rodriguez E, Cuadrado-Soto E, Navia B, Lopez-Sobaler AM, Ortega RM (2015) Estimation of salt intake assessed by urinary excretion of sodium over $24 \mathrm{~h}$ in Spanish subjects aged 7-11 years. Eur J Nutr 56(1):171-178. https://doi. org/10.1007/s00394-015-1067-y

47. Ballauff A, Kersting M, Manz F (1988) Do children have an adequate fluid intake? Water balance studies carried out at home. Ann Nutr Metab 32(5-6):332-339

48. Clark PM, Hindmarsh PC, Shiell AW, Law CM, Honour JW, Barker DJ (1996) Size at birth and adrenocortical function in childhood. Clin Endocrinol (Oxf) 45(6):721-726

49. Fujishima S, Tochikubo O, Kaneko Y (1983) Environmental and physiological characteristics in adolescents genetically predisposed to hypertension. Jpn Circ J 47(2):276-282

50. Haftenberger M, Viergutz G, Neumeister V, Hetzer G (2001) Total fluoride intake and urinary excretion in German children aged 3-6 years. Caries Res 35(6):451-457

51. Haga M, Sakata T (2010) Daily salt intake of healthy Japanese infants of 3-5 years based on sodium excretion in 24-h urine. J Nutr Sci Vitaminol (Tokyo) 56(5):305-310. https://doi. org/10.3177/jnsv.56.305

52. He FJ, Wu Y, Feng XX, Ma J, Ma Y, Wang H, Zhang J, Yuan J, Lin CP, Nowson C, MacGregor GA (2015) School based education programme to reduce salt intake in children and their families (School-EduSalt): cluster randomised controlled trial. BMJ 350:h770. https://doi.org/10.1136/bmj.h770

53. Hesse A, Classen A, Knoll M, Timmermann F, Vahlensieck W (1986) Dependence of urine composition on the age and sex of healthy subjects. Clin Chim Acta 160(2):79-86

54. Hollriegl V, Arogunjo AM, Giussani A, Michalke B, Oeh U (2011) Daily urinary excretion of uranium in members of the public of Southwest Nigeria. Sci Total Environ 412-413:344350. https://doi.org/10.1016/j.scitotenv.2011.09.023

55. Juárez López MLA, Hernández Guerrero JC, Adriano Anaya MP, Pruneda FM (2016) Urinary fluoride excretion in 3-5-year-old children with and without malnutrition. Fluoride 49(2):178-184

56. Ketley CE, Cochran JA, Holbrook WP, Sanches L, van Loveren C, Oila AM, O'Mullane DM (2004) Urinary fluoride excretion by preschool children in six European countries. Community Dent Oral Epidemiol 32(Suppl 1):62-68. https://doi.org/10.111 1/j.1600-0528.2004.00141.x

57. Ketley CE, Lennon MA (2001) Determination of fluoride intake from urinary fluoride excretion data in children drinking fluoridated school milk. Caries Res 35(4):252-257

58. Khandare AL, Rao GS, Lakshmaiah N (2002) Effect of tamarind ingestion on fluoride excretion in humans. Eur J Clin Nutr 56(1):82-85. https://doi.org/10.1038/sj.ejcn.1601287

59. Kirdpon S, Kirdpon W, Airarat W, Thepsuthammarat K, Nanakorn S (2006) Changes in urinary compositions among children after consuming prepared oral doses of aloe (Aloe vera Linn). J Med Assoc Thai 89(8):1199-1205

60. Kristbjornsdottir OK, Halldorsson TI, Thorsdottir I, Gunnarsdottir I (2012) Association between 24-h urine sodium and potassium excretion and diet quality in six-year-old children: a cross sectional study. Nutr J 11:94. https://doi. org/10.1186/1475-2891-11-94

61. Maguire A, Walls R, Steen N, Teasdale L, Landes D, Omid N, Moynihan P, Zohoori FV (2013) Urinary fluoride excretion in 6to 7-year-olds ingesting milk containing 0.5 or $0.9 \mathrm{mg}$ fluoride. Caries Res 47(4):291-298. https://doi.org/10.1159/000346549

62. Martins CC, Paiva SM, Cury JA (2011) Effect of discontinuation of fluoride intake from water and toothpaste on urinary excretion in young children. Int J Environ Res Public Health 8(6):2132-2141. https://doi.org/10.3390/ijerph8062132

63. Maruhama Y, Hikichi I, Hashimoto T, Saito F, Ninomiya K (1986) Further evidence for insulin hypersecretion not as an initial event but as a consequence of body growth and maturation in juvenile-onset obesity. Diabetes Res Clin Pract 2(2):83-90

64. Matkovic V, Ilich JZ, Andon MB, Hsieh LC, Tzagournis MA, Lagger BJ, Goel PK (1995) Urinary calcium, sodium, and bone mass of young females. Am J Clin Nutr 62(2):417-425

65. Mori M, Mori H, Hamada A, Yamori Y (2010) Taurine in morning spot urine for the useful assessment of dietary seafood intake in Japanese children and adolescents. J Biomed Sci 17(Suppl 1):S43. https://doi.org/10.1186/1423-0127-17-S1-S43

66. Padrao P, Neto M, Pinto M, Oliveira AC, Moreira A, Moreira P (2016) Urinary hydration biomarkers and dietary intake in children. Nutr Hosp 33(Suppl 3):314. https://doi.org/10.20960 /nh.314

67. Rafie N, Mohammadifard N, Khosravi A, Feizi A, Safavi SM (2017) Relationship of sodium intake with obesity among Iranian children and adolescents. ARYA Atheroscler 13(1):1-6

68. Rugg-Gunn AJ, Nunn JH, Ekanayake L, Saparamadu KD, Wright WG (1993) Urinary fluoride excretion in 4-year-old children in Sri Lanka and England. Caries Res 27(6):478-483

69. Sinaiko AR, Gomez-Marin O, Smith CL, Prineas RJ (1994) Comparison of serum calcium levels between junior high school children with high-normal and low-normal blood pressure. The child and adolescent blood pressure program. Am J Hypertens 7(12):1045-1051

70. Staessen J, Bulpitt C, Fagard R, Joossens JV, Lijnen P, Amery A (1983) Four urinary cations and blood pressure. A population study in two Belgian towns. Am J Epidemiol 117(6):676-687

71. Touitou Y, Auzeby A, Camus F, Djeridane Y (2010) Twentyfour-hour profiles of urinary excretion of calcium, magnesium, phosphorus, urea, and creatinine in healthy prepubertal boys. Clin Biochem 43(1-2):102-105. https://doi.org/10.1016/j.clinb iochem.2009.09.005

72. Villa A, Anabalón M, Cabezas L (2000) The fractional urinary fluoride excretion in young children under stable fluoride intake conditions. Commun Dent Oral Epidemiol 28(5):344-355

73. Zhang L, Zhao F, Zhang P, Gao J, Liu C, He FJ, Lin CP (2015) A pilot study to validate a standardized one-week salt estimation method evaluating salt intake and its sources for family members in China. Nutrients 7(2):751-763. https://doi.org/10.3390/nu702 0751

74. Zohouri FV, Rugg-Gunn AJ (2000) Total fluoride intake and urinary excretion in 4-year-old Iranian children residing in lowfluoride areas. Br J Nutr 83(1):15-25

75. Zohouri FV, Swinbank CM, Maguire A, Moynihan PJ (2006) Is the fluoride/creatinine ratio of a spot urine sample indicative of 24-h urinary fluoride? Community Dent Oral Epidemiol 34(2):130-138. https://doi.org/10.1111/j.1600-0528.2006.00269 .x 
76. Melse-Boonstra A, Rozendaal M, Rexwinkel H, Gerichhausen MJ, van den Briel T, Bulux J, Solomons NW, West CE (1998) Determination of discretionary salt intake in rural Guatemala and Benin to determine the iodine fortification of salt required to control iodine deficiency disorders: studies using lithium-labeled salt. Am J Clin Nutr 68(3):636-641

77. Allison ME, Walker V (1986) The sodium and potassium intake of 3 to 5 year olds. Arch Dis Child 61(2):159-163

78. Baker BA, Alexander BH, Mandel JS, Acquavella JF, Honeycutt R, Chapman P (2005) Farm family exposure study: methods and recruitment practices for a biomonitoring study of pesticide exposure. J Expo Anal Environ Epidemiol 15(6):491-499. https ://doi.org/10.1038/sj.jea.7500427

79. Chen W, Wu Y, Lin L, Tan L, Shen J, Guo X, Wang W, Bian J, Jiang W, Zhang W (2016) 24-h Urine samples are more reproducible than spot urine samples for evaluation of iodine status in school-age children. J Nutr 146(1):142-146. https://doi. org/10.3945/jn.115.215806

80. Soto-Mendez MJ, Aguilera CM, Campana-Martin L, MartinLaguna V, Schumann K, Solomons NW, Gil A (2015) Variation in hydration status within the normative range is associated with urinary biomarkers of systemic oxidative stress in Guatemalan preschool children. Am J Clin Nutr 102(4):865-872. https://doi. org/10.3945/ajen.114.105429

81. Campanozzi A, Avallone S, Barbato A, Iacone R, Russo O, De Filippo G, D’Angelo G, Pensabene L, Malamisura B, Cecere G, Micillo M, Francavilla R, Tetro A, Lombardi G, Tonelli L, Castellucci G, Ferraro L, Di Biase R, Lezo A, Salvatore S, Paoletti S, Siani A, Galeone D, Strazzullo P, Grp M-GPS (2015) High sodium and low potassium intake among italian children: relationship with age, body mass and blood pressure. PLoS One 10(4):e0121183. https://doi.org/10.1371/journal.pone.0121183

82. Grases F, Rodriguez A, Costa-Bauza A, Saez-Torres C, Rodrigo D, Gomez C, Mir-Perello C, Frontera G (2015) Factors associated with the lower prevalence of nephrolithiasis in children compared with adults. Urology 86(3):587-592. https://doi. org/10.1016/j.urology.2015.06.028

83. Manz F, Wentz A, Sichert-Hellert W (2002) The most essential nutrient: defining the adequate intake of water. J Pediatr 141(4):587-592. https://doi.org/10.1067/mpd.2002.128031

84. Higgins JPT, Thomas J, Chandler J, Cumpston M, Li T, Page MJ, Welch VA (eds) (2019) Cochrane handbook for systematic reviews of interventions version 6.0 (updated July 2019). Cochrane. www.training.cochrane.org/handbook

85. Remer T, Neubert A, Maser-Gluth C (2002) Anthropometrybased reference values for 24-h urinary creatinine excretion during growth and their use in endocrine and nutritional research. Am J Clin Nutr 75(3):561-569

86. Goldstein SL (2012) Oliguria in children. In: Vincent J-L, Hall JB (eds) Encyclopedia of intensive care medicine. Springer, Berlin, p 1616. https://doi.org/10.1007/978-3-642-00418-6_309

87. Nath SK, Moinier B, Thuillier F, Rongier M, Desjeux JF (1992) Urinary excretion of iodide and fluoride from supplemented food grade salt. Int J Vitam Nutr Res 62(1):66-72

88. Knudsen N, Christiansen E, Brandt-Christensen M, Nygaard B, Perrild H (2000) Age- and sex-adjusted iodine/creatinine ratio: A new standard in epidemiological surveys? Evaluation of three different estimates of iodine excretion based on casual urine samples and comparison to $24 \mathrm{~h}$ values. Eur J Clin Nutr 54(4):361-363

89. Konno N, Yuri K, Miura K, Kumagai M, Murakami S (1993) Clinical evaluation of the iodide/creatinine ratio of casual urine samples as an index of daily iodide excretion in a population study. Endocr J 40(1):163-169

90. Edwards OM, Bayliss RIS, Millen S (1969) Urinary creatinine excretion as an index of the completeness of 24-h urine collections. Lancet 294(7631):1165-1166. https://doi. org/10.1016/s0140-6736(69)92488-x

91. Johner SA, Boeing H, Thamm M, Remer T (2015) Urinary 24-h creatinine excretion in adults and its use as a simple tool for the estimation of daily urinary analyte excretion from analyte/creatinine ratios in populations. Eur J Clin Nutr 69(12):1336-1343. https://doi.org/10.1038/ejen.2015.121

92. Perrine CG, Cogswell ME, Swanson CA, Sullivan KM, Chen TC, Carriquiry AL, Dodd KW, Caldwell KL, Wang CY (2014) Comparison of population iodine estimates from 24-h urine and timed-spot urine samples. Thyroid. https://doi.org/10.1089/ thy.2013.0404

93. Vought RL, London WT, Lutwak L, Dublin TD (1963) Reliability of estimates of serum inorganic iodine and daily fecal and urinary iodine excretion from single casual specimens. J Clin Endocrinol Metab 23:1218-1228. https://doi.org/10.1210/ jcem-23-12-1218

94. Frey HM, Rosenlund B, Torgersen JP (1973) Value of single urine specimens in estimation of 24 hour urine iodine excretion. Acta Endocrinol (Copenh) 72(2):287-292

95. Thomson CD, Smith TE, Butler KA, Packer MA (1996) An evaluation of urinary measures of iodine and selenium status. J Trace Elem Med Biol 10(4):214-222. https://doi.org/10.1016/ S0946-672X(96)80038-1

96. Rasmussen LB, Ovesen L, Christiansen E (1999) Day-to-day and within-day variation in urinary iodine excretion. Eur J Clin Nutr 53(5):401-407

97. Konig F, Andersson M, Hotz K, Aeberli I, Zimmermann MB (2011) Ten repeat collections for urinary iodine from spot samples or 24-h samples are needed to reliably estimate individual iodine status in women. J Nutr 141(11):2049-2054. https://doi. org/10.3945/jn.111.144071

98. Als C, Helbling A, Peter K, Haldimann M, Zimmerli B, Gerber $\mathrm{H}$ (2000) Urinary iodine concentration follows a circadian rhythm: a study with 3023 spot urine samples in adults and children. J Clin Endocrinol Metab 85(4):1367-1369. https://doi. org/10.1210/jcem.85.4.6496

99. Ji C, Lu T, Dary O, Legetic B, Campbell NR, Cappuccio FP, PAHO-WHO Regional Expert Grp (2015) Systematic review of studies evaluating urinary iodine concentration as a predictor of 24-h urinary iodine excretion for estimating population iodine intake. Rev Panam Salud Publ 38(1):73-81. https://doi. org/10.1016/s0022-3476(94)70025-7

100. Xu C, Guo X, Tang J, Guo X, Lu Z, Zhang J, Bi Z (2016) Iodine nutritional status in the adult population of Shandong Province (China) prior to salt reduction program. Eur J Nutr 55(5):19331941. https://doi.org/10.1007/s00394-015-1009-8

101. Edmonds JC, McLean RM, Williams SM, Skeaff SA (2016) Urinary iodine concentration of New Zealand adults improves with mandatory fortification of bread with iodised salt but not to predicted levels. Eur J Nutr 55(3):1201-1212. https://doi. org/10.1007/s00394-015-0933-y

102. Shan Z, Chen L, Lian X, Liu C, Shi B, Shi L, Tong N, Wang S, Weng J, Zhao J, Teng X, Yu X, Lai Y, Wang W, Li C, Mao J, Li Y, Fan C, Teng W (2016) Iodine status and prevalence of thyroid disorders after introduction of mandatory universal salt iodization for 16 years in china: a cross-sectional study in 10 cities. Thyroid 26(8):1125-1130. https://doi.org/10.1089/thy.2015.0613

103. Johner S, Thamm M, Schmitz R, Remer T (2016) Examination of iodine status in the German population: an example for methodological pitfalls of the current approach of iodine status assessment. Eur J Nutr 55(3):1275-1282. https://doi.org/10.1007/s00394-015-0941-y

104. Zimmermann MB, Andersson M (2012) Assessment of iodine nutrition in populations: past, present, and future. Nutr Rev 70(10):553-570. https://doi.org/10.111 $1 /$ j.1753-4887.2012.00528.x 
105. Larsson G, Victor A (1988) Micturition patterns in a healthy female population, studied with a frequency/volume chart. Scand J Urol Nephrol Suppl 114:53-57

106. Wang CY, Cogswell ME, Loria CM, Chen TC, Pfeiffer CM, Swanson CA, Caldwell KL, Perrine CG, Carriquiry AL, Liu K, Sempos CT, Gillespie CD, Burt VL (2013) Urinary excretion of sodium, potassium, and chloride, but not iodine, varies by timing of collection in a 24-h calibration study. J Nutr 143(8):12761282. https://doi.org/10.3945/jn.113.175927

107. Soldin OP (2002) Controversies in urinary iodine determinations. Clin Biochem 35(8):575-579 